ANALES DE LA UNIVERSIDAD DE ALICANTE. HISTORIA MEDIEVAL, N. ${ }^{\circ}$ 16, (2009-2010) (pp. 111-132) I.S.S.N.: 0212-2480

\title{
LA ANDALUCÍA DE LAS CIUDADES
}

\author{
Antonio Collantes de Terán Sánchez $z^{1}$ \\ Universidad de Sevilla
}

\section{RESUMEN}

Históricamente, se ha venido considerando a Andalucía como un país de ciudades y así continuó siendo a lo largo de los siglos medievales. Partiendo del desigual nivel de información y de trabajos para el conjunto del territorio, esta aproximación a su evolución en el citado período se efectúa a través de cuatro apartados. En el primero, dedicado al sistema jurídico, se incide, por una parte, en el hecho de que los monarcas bajomedievales quisieron hacer de Sevilla un modelo de concejo, que extender a otros centros urbanos castellanos; por otra, en la función normativa de los citados concejos como cabeza de sus respectivos alfoces. Esto lleva al segundo apartado, cuyo eje es la organización territorial de Andalucía basada en el sistema de villa y tierra, con un grado de dependencia de esta con relación a aquella prácticamente total. También se analiza su papel como centros a distintas escalas y por tanto su jerarquización. El tercero trata de ofrecer una visión de conjunto de la estructura social, con especial incidencia en la paulatina configuración y diversificación de sus élites, a través de la diversidad de sus bases económicas y del ejercicio del poder local. El último apartado plantea la posibilidad de que existiesen ciertos rasgos identificativos de las ciudades andaluzas desde la perspectiva del urbanismo.

Palabras clave: siglos XIII-XV, Andalucía, sistemas jurídicos, villa y alfoz, centralidad urbana, estructura social, elites, caballeros de cuantía, veinticuatros, jurados, urbanismo.

1 Doctor en Geografía e Historia. Departamento de Historia Medieval y Ciencias y Técnicas Historiográficas. Facultad de Geografía e Historia. Universidad de Sevilla. 41004. Sevilla. C.e.: collante@us.es 


\section{ABSTRACT}

Historically, Andalusia has been considered as a country of cities and it has been this way during the medieval centuries. Taking the unequal level of information and works in the territory complex as a starting point, the rapprochement to its evolution in this period is carried out through four sections. In the first one, dedicated to the legal system, the author insists, from one hand, on the fact that the monarchs in the Low Middle Ages tried to make Seville a model of council, with the aim to extend it to other Castilian urban areas; from the other hand, he insists on the ruling function of these councils as a head of their own outlying areas. This leads to the second section, whose axis is the territorial organisation of Andalusia based on the town and land system, with an almost absolute degree of dependence of it. It is also analysed its role as centres at different scales and therefore their organization into a hierarchy. The third section tries to offer an overview to the social structure, specially to the gradual composition and diversification of their elites, through the diversity of economic basis and local power exercise. The last section considers the possibility of identifiying features in the cities of Andalusia from the perspective of towns planning.

Keywords: 13rd - 15th centuries, Andalusia, legal systems, town and council, urban centralism, social structure, elites, Knights of Rank, aldermen, jury, town planning.

Con independencia del contenido atribuible al término ciudad, la historiografía ha venido considerando a Andalucía como país de ciudades, desde la Antigüedad. Los argumentos esgrimidos han sido: sus dimensiones, el volumen de ciudadanos que han concentrado, la conciencia de su propia identidad, diferenciada de las demás, así como el desempeño de funciones de centralidad de distinto nivel y contenido, en la mayor parte de los casos.

Tras la incorporación a la Corona de Castilla de lo que, a partir de ese momento, comenzó a conocerse como Andalucía, se reafirmó la importancia de la red de ciudades, pues sobre ella se configuró la nueva ordenación territorial. Esta se inspiró en modelos ya ensayados en otras zonas castellanas y, a su vez, estuvo condicionada por la realidad de un proceso repoblador difícil, que se apoyaría, inicialmente, en los centros urbanos, para, a partir de ellos, ir poblando el espacio rural. Aquella experiencia acumulada, así como las novedades que se estaban introduciendo en Castilla cuando el citado proceso se llevaba a cabo, contribuyeron a que, según el nivel de la realidad humana enfocado, se observen continuidades y diferencias, respecto de los modelos aportados por los nuevos pobladores o con los que entraron en contacto en su nueva tierra. 


\section{1.}

Como no podía ser de otra forma, la columna vertebral de la nueva realidad, fue el sistema jurídico implantado en el siglo XIII. Mientras que a algunos centros urbanos jiennenses se les dio el fuero de Cuenca, la mayor parte de las ciudades andaluzas recibieron el de Toledo, que, a su vez, remitía al Liber. Bien es cierto, que se trató de un fuero de Toledo completado o adaptado a las nuevas realidades y con diferencias en sus versiones cordobesa y sevillana. Nuevas versiones que, a su vez, se difundieron por el resto de la región e incluso fuera de ella, en concreto, por el Reino de Murcia.

Mientras que, como es conocido, el Fuero de Cuenca, por su extensión, daba respuesta a gran parte de las necesidades de las nuevas comunidades urbanas, no ocurría así con el toledano. De ahí, que llegase acompañado de una serie de textos normativos o que enunciaban privilegios, que regían en la citada ciudad². Aun así, estos fueron insuficientes, por lo que, muy pronto, se hizo imprescindible regular numerosos aspectos de la vida ciudadana ${ }^{3}$. En consecuencia, tanto Alfonso X como sus sucesores fueron emitiendo ordenamientos y ordenanzas, que lo completaron.

En esta labor, destacó Alfonso XI, que se volcó de forma especial en el concejo sevillano, para el cual promulgó hasta siete ordenamientos, regulando los más diversos aspectos del régimen municipal, de sus competencias judiciales, administrativas o económicas ${ }^{4}$. De la importancia de dicha actuación es una buena prueba que muchas de sus disposiciones se incorporaron en las posteriores recopilaciones de ordenanzas, incluida la última de ellas, efectuada durante el reinado de los Reyes Católicos, la cual, impresa, estuvo vigente hasta el final del Antiguo Régimen. Como indica Fernández Gómez, el citado monarca quizá tuvo la intención de hacer del concejo sevillano un modelo, que ir aplicando al resto de los castellanos. Algo que se podría deducir de determinadas expresiones de una carta dirigida al de Córdoba, en la cual parece remitir a medidas

2 GonzÁlez, J.: El Repartimiento de Sevilla, Madrid, 1951, t. I, p. 325. Traslados de la citada documentación en González ArCe J. D.: Documentos medievales de Sevilla en el Archivo Municipal de Murcia. Fueros, privilegios, ordenanzas, cartas, aranceles (siglos XIII-XV), Sevilla, 2003, pp. 137-143.

3 Una visión de conjunto de los sistemas normativos aplicados o creados en Andalucía a lo largo de la Edad Media en GonzÁlez Jiménez, M.: «La creación del derecho local y territorial andaluz. De Alfonso X a los Reyes Católicos», en Initium. Revista Catalana d'Història del Dret, 9 (2004), pp. 127-222.

4 Fernández Gómez, M., en Kirschberg Schenck, D. y Fernández Gómez, M.: El concejo de Sevilla en la Edad Media (1248-1454), Sevilla, t. II, p. 75 y ss. También están publicados la mayoría en González Arce J. D.: Documentos medievales de Sevilla en el Archivo Municipal de Murcia... 
adoptadas para Sevilla5. Por otro lado, en 1376, el concejo sevillano se irrogó la representatividad de los de su reino, al solicitar a Enrique III que devolviese a todas las villas del mismo la capacidad de nombrar ciertos oficios, que les había concedido Alfonso $\mathrm{XI}^{6}$. Otro tanto se puede afirmar de diversas instituciones. Este monarca contribuyó a difundir el regimiento, que ya estaba implantado en Sevilla desde el reinado de su abuelo, Sancho IV ${ }^{\top}$; creó los fieles ejecutores, que luego aparecieron en varias ciudades andaluzas, así como la figura de los contadores. Instituciones que no solo se implantaron en Andalucía, sino también fuera de ella. Uno de sus sucesores, Juan II, además de enviar a Toledo copia del libro de ordenamientos y ordenanzas sevillano, dispuso la creación de un cuerpo de jurados según el modelo hispalense, para lo cual, se le remitieron todos los documentos que regían la citada institución. Años más tarde, esa misma documentación fue enviada, por orden de dicho monarca, desde Toledo a Murcia ${ }^{8}$. También se enviaron a Toledo las ordenanzas de los contadores ${ }^{9}$. Esta actividad legislativa manifestada por Alfonso XI fue continuada por sus sucesores, en especial, con Enrique III.

El resto de las ciudades andaluzas presenta un panorama desolador hasta los Reyes Católicos ${ }^{10}$. Hoy por hoy, no es posible concretar si dicho vacío normativo se debe a pérdidas documentales, a que los monarcas no sintieron la necesidad de intervenir ${ }^{11}$, o a que se llevó a cabo por otros caminos, en concreto, por medio de ordenanzas redactas por los corregidores, como ocurrió en Córdoba con las de $1435^{12}$.

5 García Fernández, M: «Tensiones nobiliarias y gobierno municipal en Córdoba durante la minoría de Alfonso XI», en Historia, Instituciones, Documentos, 25 (1998), p. 246. Comentado por González Jiménez, M.: «La creación del derecho local...», p. 183.

6 Archivo Municipal de Jerez (AMJ), Actas Capitulares, 1492, f. 78v.

7 Kirschberg Schenck, D., en Kirschberg Schenck, D. y Fernández Gómez, M.: El concejo de Sevilla..., t. I, p. 44 y ss.

8 Fernández Gómez, M. «Los jurados y el derecho concejil sevillano», en Fernández Gómez, M., Ostos Salcedo, P. (coords.): El Libro de privilegios de los jurados de Sevilla, Sevilla, 2010, pp. 71-76. En general, para la expansión de esta normativa sevillana a Murcia y Toledo, ver, también, Fernández Gómez, M.: El concejo de Sevilla, II, p. 15, 16; y González Arce, J. D.: Documentos medievales..., p. 69 y ss.

9 Collantes de Terán Sánchez, A.: «Los contadores del concejo sevillano en la Baja Edad Media», en Homenaje a don Antonio Domínguez Ortiz, Granada, 2008, t. I, p. 305.

${ }^{10}$ GonzÁlez JimÉnez, M.: «La creación del derecho local...», pp. 184-186.

${ }^{11}$ Esta apreciación se refiere a la ausencia de textos articulados en capítulos, que regulasen una o varias actividades o instituciones, pues lo que no se pueden negar son las intervenciones puntuales de los monarcas en temas concretos, como reflejan las actas capitulares y las recopilaciones de ordenanzas posteriores.

12 González Jiménez, M.: «Ordenanzas del concejo de Córdoba (1435)», en Historia, Instituciones, Documentos, 2 (1975), pp. 213-306. 
Por último, los respectivos concejos municipales, en virtud de sus competencias, también dictaron normas, las generalmente conocidas como ordenanzas municipales, regulando los más diversos aspectos de la vida económica, administrativa, judicial, etc., que completaban o desarrollaban las disposiciones regias. También en este campo hay que tener en cuenta su difusión más allá de cada frontera municipal y de sus respectivos alfoces. Los concejos organizados a partir del fuero de otra ciudad, recurrieron con frecuencia a esta para solicitar información e incluso sus propias ordenanzas sobre los aspectos más variados, con el fin de aplicarlas, como se observa en Écija, respecto de Córdoba; o en Carmona y Jerez de la Frontera, respecto de Sevilla, por ejemplo.

Todo este complejo sistema jurídico, desarrollado a lo largo de un período de tiempo más o menos prolongado y con posibles contradicciones, a lo que se añadían las pérdidas documentales, hizo ver la conveniencia de reunirlo en un códice, que, por una parte, conservara la citada normativa y, por otra, permitiera una consulta ágil cuando fuera necesario. En función de los que han llegado hasta la actualidad, dichas medidas se tomaron, en general, tardíamente, durante el reinado de los Reyes Católicos; en unos casos, por iniciativa regia y, en otros, por la municipal ${ }^{13}$. El resultado fue que los concejos andaluces iniciaron el trabajo de recopilar y revisar la normativa para crear estos libros de ordenanzas ${ }^{14}$ en dicho momento, y muchos vieron la luz ya entrado el siglo XVI. Otro dato importante es que las citadas compilaciones estuvieron vigentes durante varias centurias, hasta el punto de que las de varias ciudades solo se conocen por copias, manuscritas o impresas, del XVI y XVII; las de Sevilla, que salieron de la imprenta en 1527, se reeditaron sin cambios en 1632. No obstante, esta ciudad también constituye una excepción en lo que se refiere a la confección tardía de los mencionados libros. La recopilación acabada de citar fue la última de una se-

${ }^{13}$ Un documento de Jaén de 1480, pone de manifiesto que las de dicha ciudad estaban dispersas (Porras Arboleda, P. A.: Ordenanzas de la muy noble, famosa y muy leal ciudad de Jaén, guarda y defendimiento de los reinos de Castilla, Granada, 1993, p. 10). Esta fecha tan tardía de las recopilaciones quizá fuese un argumento a favor de la antes mencionada no emisión de ordenamientos por parte de los monarcas, en el sentido de que los concejos, al no disponer de un cuerpo de normas más o menos amplio, que, establecido en fechas y momentos diversos, podía ofrecer desajustes y contradicciones, no sintieron la necesidad de conservarlo unido o revisado.

${ }^{14}$ Hay que hacer una advertencia o una matización. Estos códices y libros suelen aparecer como libro de ordenanzas del tal o cual concejo, o los investigadores se refieren a ellos como libro de ordenanzas municipales. Ahora bien, dado que, en los estudios sobre los sistemas legislativos, normalmente se reserva la denominación de ordenanzas para una normativa de rango inferior, hay que tener en cuenta que los citados libros incluyen tanto ordenanzas como disposiciones procedentes de los ordenamientos emanados de la cancillería regia y de los fueros. 
rie iniciada en el siglo XIV, que fueron utilizadas por los regidores y autoridades concejiles en el desempeño de sus funciones. Quizá, la mencionada proliferación de ordenamientos regios y la complejidad de la vida ciudadana, obligaron a esa temprana recopilación de las mismas, aparte de los códices confeccionados para remitirlos a otros concejos.

\section{2.}

La unidad territorial de Andalucía desde el punto de vista institucional quedó limitada básicamente a un determinado ámbito de la administración de justicia, el que correspondió al Adelantado de Andalucía o de la Frontera, al actuar como tribunal de apelación de las jurisdicciones inferiores y como primera instancia para determinados delitos cometidos en el conjunto de la región ${ }^{15}$. En un escalón inferior se situaron los tres reinos que la conformaron: los de Córdoba, Jaén y Sevilla, los cuales, así mismo, prácticamente, solo tuvieron un reconocimiento diplomático, pues, únicamente funcionaron como distritos fiscales, aunque identificados por sus circunscripciones eclesiásticas: obispado de Córdoba, obispado de Jaén y arzobispado de Sevilla, que incluía el obispado de Cádiz. Ahora bien, la concesión de los fueros de sus capitales a las distintas entidades de población de los citados reinos, señalada en el apartado precedente, y las funciones de centralidad de aquellas pudieron dotar a cada reino de un cierto grado de integración ${ }^{16}$.

Por tanto, lo que realmente funcionó en la región, como venía ocurriendo en otras partes de la Corona de Castilla, fue la estructura de villa y tierra, en virtud de la cual, el control de amplios territorios se entregó a una ciudad que desempeñó el papel de capital ${ }^{17}$. La extensión de los alfoces o tierras fue muy desigual. Desde los $12.000 \mathrm{~km}^{2}$ de Sevilla o los 9.000 de Córdoba, hasta los 1.400 de Jerez de la Frontera o los 1.300 de Carmona. Pero con ser esto importante, lo fue aún más el número de villas y lugares y sus correspondientes vecinos, sobre los que el concejo de la capital ejerció los poderes jurisdiccionales. De ahí, que no fuese igual la capacidad de Sevilla, sobre unas 60 localidades, que la de Córdoba, sobre 21, o Jaén sobre una decena. Aparte de que algunas carecieron de entida-

\footnotetext{
${ }^{15}$ Vázquez Campos, B.: Los adelantados mayores de la Frontera o de Andalucía (siglos XIII-XIV), Sevilla, 2006, p. 381.

${ }^{16}$ Un jurado de Jerez de la Frontera llegará a afirmar que los ordenamientos concedidos a Sevilla tenían validez en el conjunto de su reino.

${ }^{17}$ Una exposición más desarrollada de este apartado se puede encontrar en ColLANTES DE Terán Sánchez, A.: "Ciudad y territorio rural en la Andalucía medieval», en La ciudad medieval y su influencia territorial. Nájera. Encuentros Internacionales del Medievo, Logroño, 2007, pp. 19-53.
} 
des de población o estas fueron insignificantes en sus respectivos alfoces, como Andujar, Antequera, Carmona, Écija o Jerez de la Frontera.

La mayor parte de las citadas poblaciones rurales tuvieron la condición de villas, por tanto, dispusieron de un concejo y de las capacidades inherentes a su condición de tales, pero siempre sometidos a la superior jurisdicción del de la capital, cuyas decisiones estuvieron por encima de las de aquellos. A diferencia de lo que ocurrió en otras partes de la Corona de Castilla, en las que esos municipios rurales, o sus vecinos, tuvieron alguna capacidad de intervención, sobre todo en temas de naturaleza fiscal, en Andalucía, los citados concejos del alfoz carecieron de órganos o mecanismos de participación, por medio de los cuales poder ser copartícipes de decisiones que les afectasen.

Dentro de los límites establecidos por la normativa regia, el concejo de la capital tenía capacidad para regular todos los aspectos de la vida corporativa, institucional y económica. Aunque las villas del alfoz podían dictar normas, estaban sometidas a la supervisión del citado. De la misma manera, las autoridades locales, elegidas por los vecinos, debían ser ratificadas o aprobadas por aquel, cuando no las elegía de una terna. En cuanto a la administración de justicia, los alcaldes de las villas entendían en pleitos civiles en primera instancia, de cuyas sentencias se apelaba a los tribunales del concejo urbano, a quien también correspondía entender en primera instancia de los delitos de naturaleza criminal, por medio de jueces designados por el.

En cuanto a los recursos económicos, por lo general, los más rentables les fueron sustraídos a las villas y asignados por los reyes al concejo de la capital. Dicho con otras palabras, el alfoz constituyó una fuente fundamental de sus recursos, hasta el punto de que cuando hay datos cuantitativos, los procedentes de este se acercan al $75 \%$ de los ingresos ordinarios. Mientras que en el terreno de los recursos ordinarios, la ciudad careció de capacidad de decisión, porque la competencia de los monarcas fue absoluta, no ocurrió lo mismo con los ingresos extraordinarios, sobre los cuales sí que la disponibilidad del citado concejo fue amplia. Pudo decidir qué parte correspondía a la ciudad y cual a las villas del alfoz; los procedimientos de recaudación; sobre qué productos o servicios, en el caso de que recurriese a impuestos indirectos; establecer los topes y los baremos, en los directos, etc., pues los monarcas, una vez fijada la cantidad a recaudar, el resto de las cuestiones normalmente las dejaron en manos de aquel.

El conjunto de competencias de los concejos urbanos sobre los de sus alfoces y sus tierras fue considerable, sin lugar a dudas, mayor que en algunas zonas de la Corona de Castilla, como consecuencia de una subrogación del poder regio ex novo en el momento de la repoblación, en el contexto de una determinada forma de estructurar la administración territorial, pero sin que, en ningún momento, la 
tutela regia dejara de ejercerse. Por tanto, también hay que tener en cuenta sus limitaciones, que fueron consecuencia de la superior capacidad de intervención de la monarquía, así como de las debilidades generales del sistema de gestión pública en esos siglos, sobre todo de las derivadas de la confluencia de intereses que se dieron en estos ámbitos locales: los de las oligarquías urbanas, los de las elites rurales, las manipulaciones de las autoridades locales en el campo fiscal, etc. En consecuencia, desde la perspectiva de la integración de las capitales de alfoz andaluzas en las estructuras de poder, si se las considera como poderes señoriales, desde luego no se las puede comparar o situar en pie de igualdad con los señores laicos o eclesiásticos, como se viene haciendo, sino más bien con las villas cabezas de alfoz sometidas a cualquiera de dichos señores, dada la inmediatez del monarca y su capacidad de control ${ }^{18}$. Todo ello, con independencia de que la terminología pueda dar a entender otra cosa, como la expresión «los señores Córdoba» que empleaban los regidores cordobeses, o la consideración de vasallos que se atribuían las autoridades de los pueblos del alfoz, cuando se dirigían al concejo sevillano.

Las funciones de centralidad de estas ciudades superaron en muchos aspectos su espacio jurisdiccional, es decir, la tierra o alfoz, para extenderse sobre otras ciudades de menor rango y sobre los territorios señorializados. Es decir, en el caso de las tres ciudades capitales de reino, sobre el conjunto de cada uno de ellos. Dichas centralidades fueron, fundamentalmente, de naturaleza administrativa, fiscal y, sobre todo, económica.

Administrativa porque, de hecho, fueron capitales señoriales. Andalucía conoció a lo largo de la Baja Edad Media un notable proceso de señorialización. Al final del citado período, el 48 \% del territorio estaba repartido entre una pluralidad de nobles e instituciones eclesiásticas. De este conjunto, sobresalió un reducido número de linajes, que conformaron la alta nobleza andaluza, gracias a la capacidad para construir grandes estados, una de cuyas características fue que tendieron a concentrarse en cada uno de los reinos, sobre todo, en los de Córdoba y Sevilla. Pues bien, aunque alguna de sus villas, en cierta medida, tuviera la condición de capital o lugar principal del señorío, los linajes residieron en ambas ciudades, en las que tuvieron sus «casas ma-

\footnotetext{
${ }^{18}$ En relación con estas cuestiones, cfr. Diago Hernando, M.: «Los señoríos territoriales de las ciudades europeas bajomedievales. Análisis comparativo de los ejemplos castellano y alemán«, en Hispania, 188, 1994, p. 804 y ss. Carpio, J. B.: La tierra de Córdoba: el dominio jurisdiccional de la ciudad durante la Baja Edad Media, Córdoba, 2000, p. 361 y ss. Monsalvo Antón, J. Ma: "Centralización monárquica castellana y territorios concejiles (algunas hipótesis a partir de las ciudades medievales de la región castellano-leonesa)», en Historia Medieval. Anales de la Universidad de Alicante 13, 2000, p. 52 y ss.
} 
yores». Por tanto, desde ellas gobernaron y a ellas acudieron quienes tenían que gestionar asuntos públicos o privados, quienes debían recurrir o apelar a los órganos superiores de la administración de justicia señorial, y hacia ellas se canalizaron parte de los beneficios obtenidos en sus dominios, los cuales se invertieron en la construcción y mantenimiento de sus residencias, en sostener el tren de vida de la familia, etc. Solo a finales del período se advierte un cierto cambio, como consecuencia de la política regia de alejarlos del poder urbano.

A su vez, la condición de cabeza de circunscripciones fiscales y de grandes mercados de las mencionadas ciudades fue otro aspecto de dicha centralidad. Villas y lugares de señorío estaban integrados en distritos fiscales junto con los de realengo. En cuanto a lo económico, la importancia de dichos centros urbanos contribuyó a generar una serie de relaciones de esta naturaleza con localidades no sometidas a su jurisdicción. Por un lado, fueron de carácter institucional, en tanto en cuanto se trataba de reconocimientos que tenían contenido económico o de fijación de precios, patrones de pesos y medidas, etc. Por otro, los flujos de mercancías que, de forma creciente, circularon en las dos direcciones, pero en los que predominó la que se dirigía a los mercados urbanos, como consecuencia de su importancia.

Esa preeminencia de las tres capitales, respecto de las restantes villas y ciudades de sus reinos, se manifestó institucionalmente en el hecho de que acabaron siendo las únicas andaluzas con presencia en las reuniones de Cortes y Ayuntamientos. Pero también hubo otras formas de manifestarse. Por ejemplo, en Jaén, según privilegio de Enrique III, cuando las milicias concejiles partían para operaciones militares, los pendones de los concejos de su reino debían esperar y escoltar al de la ciudad de Jaén ${ }^{19}$.

\section{3.}

Estas diferencias político-administrativas y funcionales entre las ciudades y el mundo rural, así como la superioridad de aquellas respecto de este, se trasladaron a la conciencia de sus habitantes. Quizás las más evidentes fueron las económicas. En general, los vecinos de las ciudades gozaron de exenciones y ventajas comerciales, que les estuvieron vedadas a los de sus respectivos alfoces. Por ejemplo, estos no se beneficiaron de las oportunidades que ofrecían los más o menos importantes mercados urbanos, al no poder introducir sus productos en ellos sin pagar derechos de entrada o de otra naturaleza, lo que sí pudieron

\footnotetext{
${ }^{19}$ Rodríguez Molina, J.: La ciudad de Jaén. Inventario de sus documentos (1549-1727), Jaén, 1982, p. 48. Porras, P. A.: Ordenanzas..., p. 8, 9.
} 
hacer aquellos. En otro nivel, mientras que los residentes en los pueblos utilizaron el término vasallo para dirigirse a las autoridades urbanas; los de las ciudades reclamaron para ellas títulos de noble, leal, etc. Algún autor ha aludido a la existencia de un humanismo cívico al referirse a la Sevilla del siglo XV; por otro lado, la presencia de dichas ciudades en las creaciones literarias de estas centurias, ya sea dentro del género laudes civitatis, o como medio de atraerse el autor la benevolencia del mecenas de turno, reflejan esa conciencia de superioridad ${ }^{20}$. Los ejemplos se pueden rastrear desde la propia Primera Crónica General hasta finales de la Edad Media, con obras como la descripción de Córdoba, por un clérigo llamado Jerónimo, o la de Sevilla, en una carta que Alonso de Palencia dirigió a un arcediano de Carrión, que había nacido en aquella ${ }^{21}$.

También a través de actos y ceremonias cívicas y/o cívico-religiosas, como en el conjunto europeo. La más difundida fue la procesión del Corpus, con la presencia de los distintos estamentos y sectores de las respectivas sociedades urbanas. Aunque se trata de algo conocido ${ }^{22}$, quizá convenga reseñar cómo en las ciudades medianas o pequeñas, los conflictos entre distintas corporaciones por su posición en el cortejo o por ir o no junto con otras más o menos afines, ponen de manifiesto el valor otorgado a este tipo de representaciones del cuerpo social. Su importancia viene corroborada por el hecho de que distintos aspectos de la citada fiesta y procesión aparecen regulados en las ordenanzas municipales que se recopilaron a finales del siglo XV y en el siguiente, como en las de Carmona, Écija, Jaén o Jerez de la Frontera23. También habría que considerar las ceremonias destinadas a conmemorar la conquista de las ciudades por los castellanos, de las cuales, la mejor conocida es la que, todavía hoy, tiene lugar, cada año, en Sevilla24.

${ }^{20}$ TAte, B.: «The civic humanisme of Alfonso de Palencia», en Nottingham Renaissance and Modern Studies, XXIII, 1979, pp. 25-44. Ibid.: «Laus urbium: Praise of Two Andalusian Cities in the Mid-Fifteenh Century», en Medieval Spain. Culture, Conflicty and Coexistence, R. Collins and A. Goodman, eds., New York, 2002, pp. 148-159. LidA DE Malkiel, Ma R.: «La ciudad, tema poético de tono juglaresco en el Cancionero de Baena», en Estudios sobre la literatura española del siglo XV, Madrid, 1978, p. 333 y ss.

${ }^{21}$ Nieto Cumplido, M.: Córdoba en el siglo XV, Córdoba, 1973. Palencia, A. DE: Epístolas latinas, ed. y traduc. R. B. Tate y R. Alemany Ferrer, Barcelona, 1982, pp. 34-41.

${ }^{22}$ Conviene llamar la atención sobre el hecho que toda la literatura existente sobre el Corpus está referida a ciudades, nunca a su papel en el medio rural.

23 Ordenanzas del concejo de Carmona, ed. y est. M. González Jiménez, Sevilla, 1972, pp. 9-10. Martín Ojeda, M.: Ordenanzas del concejo de Écija (1465-1600), Écija, 1990, p. 288 y ss. PoRRAS, P. A.: Ordenanzas..., p. 105 y ss. Recopilación de las ordenanzas del concejo de Xerez de la Frontera. Siglos XV-XVI, ed. y est. Ma A. Carmona Ruiz y E. Martín Gutiérrez, Cádiz, 2010, pp. 385-386.

${ }^{24}$ Romero Abao, A. del R.: «Las fiestas de Sevilla en el siglo XV», en Ceira, 2, 1991, p. 77. 
Otro símbolo del cuerpo social fue el pendón de la ciudad ${ }^{25}$, de ahí que, en torno al mismo, surgiese todo un conjunto de actitudes y ceremonias, que reflejaban dicha condición de símbolo. Por ejemplo, su presencia al frente de la milicia concejil dependía de la importancia de la operación militar. Para las de menor alcance, con la participación de un cuerpo reducido de combatientes, no se consideraba digno que saliese y era sustituido por el que habitualmente se denominaba pendón chico. Al igual que ocurrió en otras ciudades, ese valor simbólico quedó de manifiesto en el hecho de que no se podía inclinar ante nadie; de ahí, las medidas que se adoptaron para evitar que así ocurriese al traspasar las puertas de la ciudad. Dado que solía estar custodiado en la catedral o iglesia mayor, las autoridades municipales invitaban a todos los ciudadanos a participar en las ceremonias de entrega y recepción al capitán del ejército o al alférez. Ceremonias que no debieron ser excepcionales, por la condición fronteriza de la región y la frecuencia de las acciones militares contra el reino granadino ${ }^{26}$.

Esos miembros que desfilaron en la procesión del Corpus, fueron los que, poco a poco, dotaron de matices a las sociedades urbanas. Así, por ejemplo, en el terreno fiscal, algo las diferenció del resto de la Corona de Castilla -con la excepción de Murcia-, me refiero al hecho de que no existió tanta separación entre los sectores comúnmente denominados privilegiados y pecheros. La nobleza contribuyó en los pedidos concedidos por las Cortes, mientras que un importante sector de los sociológicamente pecheros, quedaron exentos de los servicios aprobados en las mismas ${ }^{27}$. Hubo que esperar a finales de la Edad Media, a raíz de los cambios introducidos en los sistemas fiscales, como los nuevos servicios de Cortes y los encabezamientos de alcabalas, para acabar con aquella igualdad, y la consiguiente equiparación de los privilegiados a los del resto de la Corona ${ }^{28}$.

${ }^{25}$ Mientras que las villas del alfoz de Sevilla contaron con su sello concejil, no hay constancia de que poseyesen su propio pendón, pues acudieron a las operaciones militares bajo el de Sevilla.

26 Sancho de Sopranis, H.: Historia Social de Jerez de la Frontera al fin de la Edad Media, Jerez de la Frontera, 1959, t. I, p. 34; t. III, p. 70. Carriazo Arroquia, J. de M.: En la Frontera de Granada, t. I, Sevilla, 1971, p. 540.

${ }^{27}$ La historiografía tiende a emplear el término pechero para los no integrados en los grupos de hidalgos y/o caballeros. Sin embargo, en la Andalucía medieval dicha expresión, como acabo de indicar, no es del todo clara, la única exención que disfrutaron los caballeros fue la de la moneda forera y la de las monedas aprobadas por las Cortes, pero en el caso de la ciudad de Sevilla, ni siquiera esta, porque estuvieron exentos de monedas todos los vecinos. Por otro lado, muchos no privilegiados sociológicamente sí estuvieron exentos de esos impuestos directos o servicios, los denominados francos.

${ }^{28}$ Quintanilla, M ${ }^{\text {a }}$ C. y Asenjo, Ma: «Los hidalgos en la sociedad andaluza a fines de la Edad Media», en Las ciudadesd andaluzas (siglos XIII-XVI). Actas del VI Coloquio Internacional de Historia Medieval de Andalucía, Málaga, 1991, pp. 431, 432. Collantes de Terán Sánchez, A.: «Los sevillanos ante el fisco (siglos XIII-XVI)», en Congreso Internacional «Fiscalidad y sociedad en el Mediterráneo Bajomedieval», Málaga (en prensa). 
Desde una perspectiva más sociológica, el punto de partida también fue uniforme en el conjunto de las ciudades y villas. Todos los repartimientos y cartas pueblas aluden, básicamente, a caballeros hidalgos, caballeros ciudadanos/villanos y peones. Unos y otros recibieron más o menos privilegios, que, a su vez, los diferenciaron de quienes habitaron en el medio rural. No obstante, muy pronto, las distintas situaciones geoestratégicas, estructurales y/o políticas, contribuyeron a una evolución más o menos diferente de esas sociedades urbanas, en el sentido de generarse una creciente complejidad social con ritmos y características específicas en cada una. Los rasgos fundamentales del citado proceso fueron: a) La consolidación de una élite sociopolítica procedente de aquellos caballeros de los repartimientos y de otros llegados más tarde, tanto hidalgos como ciudadanos. b) Por lo que respecta a la inmensa mayoría de peones, la individualización de los francos, es decir, de quienes, por desempeñar determinados oficios, pudieron disfrutar de una serie de exenciones fiscales muy superiores incluso a las de los caballeros hidalgos. Colectivo que, en algunas ciudades andaluzas, alcanzó cifras elevadas, pues, además, consiguieron extender los citados beneficios a sus viudas. c) La emergencia de una élite procedente de caballeros y peones que, sin llegar a formar parte de la sociopolítica, utilizó sus conocimientos e influencias de todo tipo para mostrarse como grupo diferenciado con relación a los estratos inferiores de la sociedad urbana. Aunque hay importantes trabajos, el déficit de estudios sobre esos diferentes aspectos en cada una de las ciudades andaluzas es considerable, de ahí que algunos de los comentarios que siguen tengan un alto grado de provisionalidad.

Dentro de la élite sociopolítica se puede observar un doble proceso. Por un lado, sus miembros, los denominados caballeros, aparecen claramente diferenciados: hidalgos y ciudadanos/villanos o de cuantía. De hecho, surgieron importantes conflictos entre ambos colectivos por el desempeño de cargos públicos a fines del siglo XIII y primeras décadas del XIV. Sin embargo, a lo largo de esta centuria, se inició un proceso de identificación y fusión, hasta el punto de que, a finales de la Edad Media, la citada distinción había quedado obsoleta ${ }^{29}$. Por otro lado, como en el resto de los centros urbanos castellanos, se pueden apreciar factores diferenciadores en la composición de dichas élites. Sin excluir en ningún

29 Sánchez Saus, R.: La nobleza andaluza en la Edad Media, Granada, 2005. Sin embargo, hay que dejar constancia de que existe un importante déficit en la clarificación de términos aplicados a los caballeros, como ennoblecimiento o aristocratización. En este sentido, conviene tener en cuenta las consideraciones de Enrique Soria, que, referidas a la época moderna, son válidas para la medieval («Los estudios sobre las oligarquías municipales en la Castilla moderna. Un balance en claroscuro», Manuscrits, 18, 2000, pp. 189-190). 
caso la pertenencia a las mismas de otros grupos, en las ciudades más próximas a la frontera con el Reino de Granada, la guerra posibilitó la consolidación en ellas de individuos más volcados hacia la función militar; en las que acabaron integradas en estados señoriales, la pertenencia a la misma de personas vinculadas a sus titulares; en las ciudades realengas de tipo medio, muy ligadas a las rentas de la tierra, la condición de grandes o medianos propietarios o poseedores de tierras y/o ganados les consolidaría como élite, mientras que en las ubicadas en la costa atlántica, fueron las actividades marineras y marítimas las que le dieron esa posibilidad. En fin, en los grandes centros urbanos, pronto se debió hacer evidente la complejidad de su composición social. Es más, quizá en ellas, más que en las restantes, pudiera ser más lento el proceso de cierre, que, de todas formas, en ningún caso se completó ${ }^{30}$.

Desde el primer momento, los caballeros adquirieron protagonismo en el gobierno de las ciudades, incluida la fase inicial, en la que existieron unos concejos con amplia participación ciudadana. Al implantarse los regimientos se afirmó su condición de élite política. En principio, como demostrara D. Kirschberg, esta nueva fase pudo tener su origen en Sevilla, por iniciativa del propio concejo, que, en 1286, designó a veinticuatro caballeros para que, en lo sucesivo, fuesen los responsables del gobierno municipal junto con los oficiales mayores $^{31}$, correspondiendo a Alfonso XI se extensión a otras ciudades. Las diferencias sociológicas más arriba enunciadas se hicieron realidad en la composición del mismo. Desde la paridad de hidalgos y ciudadanos establecida en Sevilla, hasta los vaivenes de las alternativas que, a través de sucesivas decisiones, tomaron los monarcas respecto de los de algunas ciudades jiennenses, como Baeza y Úbeda, precisamente como consecuencia de los conflictos surgidos entre hidalgos y ciudadanos, a raíz del establecimiento del nuevo sistema municipal. Ahora bien, en los casos en los que existieron cuotas sociales, la impresión es que estas desaparecieron con el paso del tiempo, al menos en los mayores centros urbanos, por la

30 Sánchez Saus, R.: La nobleza andaluza... El déficit de trabajos sobre las élites andaluzas es evidente. Los pocos existentes se han centrado en el siglo XV, quizá porque en esta centuria hay una documentación más abundante. Aún así, los estudios se reducen a unas pocas ciudades. Cfr. Collantes de Terán SÁnchez, A.: «La ciudad medieval andaluza: balance y propuestas para el futuro», Actas del VII Congreso de Historia Medieval de Andalucía, Granada, 2010, pp. 81-104.

${ }^{31}$ El concejo de Sevilla..., t. I, p. 44 y ss. Luego, solicitaron su aprobación al monarca, que se la concedió, lo que aprovechó para cambiar a alguno de los nombrados. Quizá por estos años también se constituyó en Córdoba, pues, en la dirección de una carta de 1297, Fernando IV alude a quince hombres buenos, «que habedes de haber fecho del concejo» (M. Gonzálezz JimÉnEz: «Los municipios andaluces en la Baja Edad Media», Archivo Hispalense, 210, 1986 p. 73). 
mencionada fusión de ambas caballerías. De todas formas, este es un tema que está por estudiar.

Otro hecho a tener en cuenta es la presión de las élites por participar de ese poder, lo cual se manifestó a través del incremento de los miembros del regimiento, algo que se detecta muy pronto en Sevilla y Córdoba, sobre todo coincidiendo con momentos de crisis política y que, con alternativas, se mantuvo hasta el final de la Edad Media. El mencionado incremento se efectuó por dos vías. Mediante la decisión -o concesión- regia de aumentar el número de miembros, hasta un total de veinticuatro ${ }^{32}$. La otra vía fue a través de los denominados «oficios acrecentados», es decir, de la proliferación de nombramientos individualizados de regidores, procedimiento al que recurrieron todos los monarcas, pero especialmente Juan II y Enrique IV. Los Reyes Católicos trataron de volver a las situaciones iniciales, lo que no siempre consiguieron completamente ${ }^{33}$. Cuando los citados procedimientos no fueron suficientes para que los miembros de la élite accedieran a esas esferas de poder, se introdujeron en otras instituciones de rango inferior y/o reservadas a los restantes sectores de la sociedad urbana, especialmente en las juraderías.

La instauración del regimiento, además de favorecer la oligarquización del poder municipal ${ }^{34}$, contribuyó a acentuar el control de las ciudades por parte de los reyes, pues si bien, en algunos casos, la elección de sus miembros partió de los propios municipios, directa o indirectamente, acabarían siendo de designación regia. Ahora bien, el citado control monárquico, se había iniciado en la mayor parte de las ciudades en el mismo momento de la instauración del régimen municipal, pues el nombramiento de los oficiales mayores se los reservó el rey: jueces, alcaldes y alguaciles mayores, fundamentalmente. En los casos en que no fue así, paulatinamente se manifestó esa voluntad regia, de forma directa o indirecta. En Córdoba, muy poco después de la concesión del fuero, de hecho, se derogó el precepto que otorgaba dicha elección a los ciudadanos. En Jerez de

32 En su origen oscilaron entre ocho y trece regidores, según las ciudades. A partir de ese momento se institucionalizó la denominación de veinticuatros. Curiosamente, el número de regidores que había tenido Sevilla desde su creación, lo que daría a entender, una vez más, que dicha ciudad sirvió de referencia para el resto de las andaluzas.

${ }^{33}$ Navarro Saínz, J. Ma: El concejo de Sevilla en el reinado de Isabel I (1474-1504), Sevilla, 2007, p. 184.

${ }^{34}$ Ante la falta de estudios en profundidad sobre la composición e integrantes de los órganos principales del gobierno urbano, planteo la duda de si en las mayores ciudades andaluzas se puede establecer una correlación entre oligarquía y élite social, y, por otro, el momento de dicha correlación. Un punto de partida para este tipo de análisis puede ser la obra de R. SÁnchez Saus: Las élites políticas bajo los Trastámara. Poder y sociedad en la Sevilla del siglo XIV (Sevilla, 2009), centrado en los años del reinado de Juan I. 
la Frontera, aunque los alcaldes mayores fueron designados por los regidores, no hay que olvidar que estos eran nombrados por los reyes ${ }^{35}$. También hay que reseñar que, a lo largo de los siglos XIV y XV, aparte de incrementarse el número de los alcaldes mayores en las principales ciudades, accedieron a las citadas magistraturas los miembros de la alta nobleza local o regional. El paso siguiente en el proceso de afirmación del control regio fue la implantación de los corregidores y otras figuras de similar cometido, cuya presencia implicó el cese en sus funciones de los alcaldes y alguacil mayores, durante el desempeño de su mandato.

Paralelamente, los monarcas habían ido introduciendo otros mecanismos de control de los gobiernos urbanos. En los momentos de constitución de los concejos, por medio de la creación de los jurados, establecidos en las ciudades a fuero de Córdoba o de Sevilla, y de los personeros, en las vinculadas al de Cuenca. Más adelante, en el siglo XIV, al instaurar la figura de los contadores, con funciones de intervención de la gestión económica municipal, y, en parte, la de los fieles ejecutores, encargados, sobre todo, del control de las actividades económicas urbanas, especialmente del mercado y del artesanado.

Las bases agrarias de la mayor parte de los centros urbanos andaluces medianos y pequeños- hicieron que la tónica dominante en las actividades del resto de dichas sociedades fuesen las relacionadas con aquellas, con independencia de que se pudiesen compaginar con las de transformación o con las de servicio, sectores que dominaron el mundo del trabajo en las ciudades mayores. Desde la perspectiva del ejercicio del poder, al crearse el regimiento, este amplio colectivo quedó marginado de los centros de decisión, pero parece que dicha marginación no siempre fue total. En 1431, en Jerez de la Frontera, asistieron a varias sesiones capitulares hasta 32 «hombres buenos»; en varios cabildos del año 1433 también estuvo presente un cierto número de vecinos; en 1460, se recabó la opinión de caballeros y vecinos; finalmente, en 1515, se solicitó, de nuevo, la opinión de los vecinos -expresada en reuniones efectuadas en cada collación- sobre el encabezamiento de las alcabalas ${ }^{36}$. Desgraciadamente, la falta de actas capitulares hasta fechas muy tardías dificulta este tipo de aproximación en el conjunto de las ciudades andaluzas, aunque quizá sea posible avanzar más en esta línea.

\footnotetext{
${ }^{35}$ Abellán Pérez, J.: El concejo de Jerez de la Frontera en la primera mitad del siglo XV: composición, sistemas de elección y funcionamiento del cabildo, Jerez de la Frontera, 1990, p. 45.

${ }^{36}$ En todas estas ocasiones, dicha participación estuvo en relación con demandas de carácter económico (AMJF, Act. Cap., 1431, f. 63, 66v.; 1433, f. 67; 1460, f. 35v, 36, 48. Collantes de Terán Sánchez, A.: «El encabezamiento de Jerez de la Frontera de 1515», en Estudios de Historia Moderna en homenaje al profesor Antonio García-Baquero, León Carlos Álvarez Santaló coord., Sevilla, 2009, pp. 311-320).
} 
También les estuvo reservada la elección de cargos municipales. En Jaén, los alcaldes ordinarios y el alguacil mayor, que eran las máximas autoridades locales ${ }^{37}$. En otras ciudades, así mismo los alcaldes ordinarios -que, a diferencia de Jaén, ocupaban un segundo escalón- y sus escribanos, cuando rotaban anualmente entre las distintas collaciones, como ocurrió en Jerez de la Frontera ${ }^{38}$. Mayor importancia tuvo la posibilidad de elegir al personero del común y a los jurados. En el caso de los últimos, al ser representantes de cada collación, fueron sus vecinos quienes los designaron, con independencia de que, poco a poco, se fueran introduciendo corruptelas. En Sevilla, Jaén y Jerez de la Frontera hay pruebas de los conflictos que podían estallar en los procesos electorales entre los propios vecinos y entre estos y los regidores, así como la paulatina introducción de la renuncia ${ }^{39}$. Por otro lado, en momentos de crisis del poder aparecen algunos ciudadanos con cierto protagonismo político o administrativo, como ocurrió en varias ciudades en la década de $1460^{40}$. En Sevilla, en 1469, varios artesanos fueron designados para llevar el control de la venta de productos básicos, como el pan, la carne y el pescado, en una actuación que parece excepcional, y debida a la incapacidad de los responsables del cumplimiento de la normativa para controlar el fraude ${ }^{41}$.

Ahora bien, es probable que la mayor parte de los que tuvieron uno u otro protagonismo pertenecieran a lo que se podría denominar una élite. Me refiero a personas que, por su riqueza y capacidad de influencia, se elevaron sobre la condición del común de los vecinos, y configuraron un estrato intermedio entre estos y la élite sociopolítica. En los centros de tipo medio, pudieron ser arrendatarios de grandes propiedades, arrendatarios de impuestos y servicios, escribanos públicos; mientras que en los mayores se añadirían a los citados, grandes financieros y mercaderes, algunos miembros del artesanado -los cuales compatibilizarían dicha actividad con la comercial-, conocedores del derecho, en especial, los vinculados a las administraciones, en concreto, a la municipal, al desempeñar el oficio de letrado o de lugarteniente de oficiales mayores, etc.; algunos de los cuales añadieron su condición de conversos. Precisamente porque la riqueza es

\footnotetext{
${ }^{37}$ Ramos Vázquez, I.: El concejo de Jaén (1474-1556), Jaén, 2002, p. 51,ss. El alguacil mayor pronto pasó a ser designado por el rey (ibid., p. 437).

38 Abellán, J.: El concejo de Jerez de la Frontera..., p. 94 y ss.

39 Abellán, J.: El concejo de Jerez de la Frontera..., p. 59 y ss. NAvarro, J. Ma: El concejo de Sevilla..., p. 368 y ss. Ramos Vázquez, I.: El concejo de Jaén..., p. 529 y ss.

${ }^{40}$ Palencia, A. de: Crónica de Enrique IV, ed. Paz y Melia, Madrid, 1973, t. I, pp. 141 y ss.

${ }^{41}$ AMS, Sec. 15, 1470.
} 
el factor diferencial y de ella se podía derivar cierta capacidad de poder, y porque muchos de sus miembros vinculados al mundo del comercio y de las finanzas se insertaron en los entramados financieros de la Corona, municipios y señoríos ${ }^{42}$, justifica, desde mi punto de vista, que se la pueda calificar de élite económica ${ }^{43}$.

Es más, dicha riqueza les obligó a formar parte de un colectivo al que se le reconoció su capacidad de promoción social: el de los caballeros ciudadanos/ villanos o de cuantía. Aparte de que de ellos procedieron los que acabaron integrados en la élite sociopolítica, los que no lo consiguieron, pudieron recibir cierta atención por parte de los regidores y desempeñar determinadas funciones. Ya he indicado cómo, en algunas ocasiones, acudieron los caballeros jerezanos junto con los restantes vecinos a sesiones capitulares, pero es que la presencia de ellos solos (sin los demás vecinos) fue más frecuente ${ }^{44}$. A su vez, los caballeros de cuantía de Córdoba eran los encargados de elegir los alcaldes ordinarios.

Además, si bien quedaron excluidos de los órganos de decisión, no ocurrió así por lo que se refiere al ejercicio de cargos públicos de segundo nivel. En algunos municipios les estuvieron reservados esos cargos, y en los que no, cabe sospechar que lo serían en muchos casos. Entre los citados se encontraban los alcaldes ordinarios, escribanos, fieles, etc., pero sobre todo los jurados y los mayordomos del cabildo. Estos por razones obvias de su papel como gestores de las finanzas concejiles, aquellos por su importancia y, finalmente, prestigio social. En el caso de los jurados sevillanos, en un primer momento, la mitad debían proceder de la caballería de cuantía, sin embargo, con el paso del tiempo dicha condición desapareció, lo que no quiere decir que la mayoría de ellos no pertenecieran a la citada caballería. Entre otras cosas, porque eso les permitió acceder a otros cargos o funciones, algunas de gran relevancia, como las de procuradores a Cortes, mandaderos del concejo ante el rey o sus oficiales mayores, fieles ejecutores, etc. Hay que tener en cuenta que la función de los jurados fue doble. Por

${ }^{42}$ Ver, al respecto, las consideraciones sobre la condición de «servidores» del rey que invocan en alguna ocasión los arrendatarios o sobre el «poder fiscal» en D. Alonso García: «Un mundo de financieros. La Hacienda Real de Castilla y sus arrendadores en las postrimerías del reinado» (L. Ribot, J. VAldeón y E. Maza (coords.), Isabel la Católica y su época. Actas del Congreso Internacional 2004, Valladolid, 2007, vol. I, p. 499 y ss.).

${ }^{43}$ Collantes de Terán Sánchez, A.: «La élite financiera en la Sevilla bajomedieval: los mayordomos del concejo», Revista d'Història Medieval, 11, 2000, pp. 13-39. Se han empleado distintas expresiones para identificar a dicho grupo, como las de élite de participación (Juan Antonio Jara), o élite del común ( $\mathrm{M}^{\mathrm{a}}$ Isabel del Val Valdivieso).

${ }^{44}$ A modo de ejemplo, en 1482, se convocó a dos caballeros por collación para tratar de las guardas de la frontera y su financiación (AMJF, Act. Cap., 1482, f. 57, 58). 
un lado, controlar las decisiones capitulares, para lo cual tenían la facultad de asistir a los cabildos con voz, pero sin voto, y la de presentar «requerimientos»; por otro, dar cuenta al rey del comportamiento de los regidores y de todo aquello que considerasen pertinente para el buen gobierno de la ciudad. Por lo que se refiere a los sevillanos, algunos de ellos, además, fueron designados por los reyes para el desempeño de misiones concretas. De todo lo cual quedan abundantes muestras en la documentación municipal ${ }^{45}$.

Esas posibilidades, unidas, una vez más, a la riqueza, es lo que ha llevado a la historiografía andaluza a identificar a los jurados con esa élite que he denominado económica, aunque, sin lugar a dudas, no se circunscribió a los que ejercieron el citado oficio. Hay varios hechos que podrían justificar dicha identificación. En primer lugar, su condición de francos, en ocasiones, en un grado muy superior a cualquier otro colectivo ${ }^{46}$. La misma aspiración a ejercer el oficio, así como la tendencia a su patrimonialización. En fin, el identificar entre sus miembros actitudes vitales propias del estamento nobiliario ${ }^{47}$, en el cual acabaron integrados. No obstante, está por estudiar la procedencia social de sus miembros a lo largo de estas centurias y los ritmos del mencionado proceso $^{48}$. Es posible que se acelerase ya avanzado el siglo XV, cuando en las principales ciudades se acentuó la ingerencia de los regidores en los procesos de elección de los jurados, si bien, según algunos autores, se puede observar en Córdoba a fines del siglo XIV y en Jerez de la Frontera en las primeras décadas del XV. Pero, por otro lado, la proliferación de «requerimientos» dirigidos a los capitulares, que se conservan en Córdoba y en las actas capitulares de Sevilla de la centuria decimoquinta, podría

\footnotetext{
45 Pino García, J. L del: «El concejo de Córdoba a fines de la Edad Media: estructura interna y política municipal», en Historia, Instituciones, Documentos, 20, 1993, pp. 369 y ss. CABRera Sánchez, M.: Nobleza, oligarquía y poder en Córdoba al final de la Edad Media, Córdoba, 1998, p. 127 y ss. Fernández Gómez, M., Ostos Salcedo, P. (coords.): El Libro de privilegios de los jurados... Velasco García, C.: Extracción social, relaciones y competencias de los regidores jiennenses en el siglo XV, Jaén, 1987, pp. 67 y ss. Abellán Pérez, J.: El concejo de Jerez de la Frontera en la primera mitad del siglo XV: composición, sistemas de elección y funcionamiento del cabildo, Jerez de la Frontera, 1990, pp. 59 y ss.

${ }^{46}$ En el caso de quienes no pudieron acceder a una juradería, se dedicaron a comprar sus franquicias a los que las disfrutaban por razón de su oficio. En este sentido, los jurados sevillanos denunciaron con reiteración la compra de dichas franquezas a los monederos, trabajadores del Alcázar y de las Atarazanas, etc., a consecuencia de lo cual, los ricos quedaban exentos y los pobres eran los que pagaban. Así, en las nóminas de francos de las citadas actividades aparecen numerosos traperos, sastres, cambiadores, candeleros, zapateros, y un largo etc. (Collantes de Terán Sánchez, A.: Sevilla en la Baja Edad Media. La ciudad y sus hombres, Sevilla, 1977, pp. 237, 238).

${ }^{47}$ Collantes de Terán Sánchez, A.: «Los jurados en la sociedad sevillana», en Fernández Gómez, M., Ostos Salcedo, P. (coords.): El Libro de privilegios de los jurados..., pp. 97 y ss.

${ }^{48}$ Collantes de Terán Sánchez, A.: «La ciudad medieval andaluza...».
} 
ser un argumento a favor de que, en esos tiempos, aun no se había producido una total confluencia de intereses ${ }^{49}$.

Si bien el conocimiento del papel del común en las ciudades andaluzas apenas está esbozado, pues lo normal es que la aproximación al mismo se haya hecho a través de la figura de los jurados, la impresión que se saca de un recorrido por las actas capitulares de algunos concejos es su falta de protagonismo, al menos, tal y como se manifiesta en centros urbanos de la Meseta ${ }^{50}$. Quizá la existencia de dichos jurados, al ser quienes pudieron canalizar sus intereses y quejas, contribuyó a la mencionada ausencia de protagonismo del común.

\section{4.}

Este último apartado trata de plantear la posible existencia de unos ciertos rasgos identificativos de las ciudades andaluzas desde la perspectiva del urbanismo, sin atribuir a dichos rasgos carácter de exclusividad. El proceso de ocupación seguido en todas ellas presenta gran similitud, con independencia de que la conquista fuese consecuencia de acuerdos más o menos rápidos, o tras asedios más o menos prolongados. Los vencidos tuvieron que abandonarlas, y fueron sustituidos por unos nuevos pobladores, venidos del norte. Dado que el cambio se produjo en un momento en el que el hecho urbano ya estaba plenamente consolidado entre los castellanos, con la llegada de los nuevos pobladores se haría realidad la confrontación de dos modelos: el oriental y el occidental. Como, debido a la forma en que tuvo lugar su incorporación a la Corona de Castilla, las ciudades pasaron de unas manos a otras, no solo prácticamente intactas, sino, incluso se podría decir, de forma figurada, que «en pleno funcionamiento», según refleja la documentación generada en la fase inicial, quiere decir que los nuevos pobladores habitaron un medio que es posible que para muchos, quizá la mayoría, fuese extraño. Por tanto, es conveniente plantearse cómo esa nueva sociedad usó unas ciudades concebidas bajo otros parámetros.

Es cierto que, desde los primeros momentos, fueron introduciendo una serie de novedades, reflejo de la nueva cultura urbana que aportaron los recién llega-

\footnotetext{
${ }^{49}$ Nieto Cumplido, M.: «Luchas nobiliarias y movimientos populares en Córdoba a fines del siglo XIV», en Tres estudios de historia medieval andaluza, Córdoba, 1977, p. 51. Abellán PéREZ, J.: El concejo de Jerez de la Frontera..., pp. 60 y ss. Mazo Romero, F.: «Problemas internos y tensiones sociales en el municipio cordobés durante la primera mitad del siglo $\mathrm{XV}$ », en Andalucía Medieval: nuevos estudios, Córdoba, 1979, pp. 175 y ss. Collantes de Terán SánCHEZ, A.: «Un requerimiento de los jurados al concejo sevillano a mediados del siglo XV», en Historia, Instituciones, Documentos, 1, 1974, pp. 41-74.

${ }^{50}$ VAl Valdivieso, M ${ }^{a}$ I. del.: «Aspiraciones y actitudes socio-políticas. Una aproximación a la sociedad urbana de la Castilla bajomedieval», en J. A. BonAchíA: La ciudad medieval, Valladolid, 1996, pp. 213-254.
} 
dos, pero también lo es, que estos mismos no dejaron de asimilar elementos de dicha ciudad heredada. Si a ello se le suma el factor económico, el resultado fue una muy lenta transformación de su entorno vital, hasta el punto de que, transcurridos varios siglos, todavía era perceptible la pervivencia de elementos o formas heredadas. A su vez, los centros urbanos crecieron, por tanto, las operaciones de nueva urbanización se desarrollaron según el modelo occidental. Resultado de todo ello fue que las ciudades andaluzas presentaron una mezcla de continuidad y de cambios, cuyos ritmos dependieron de su vitalidad; es decir, del mayor o menor grado de desarrollo experimentado a lo largo de los siglos XIII al XV.

Desde la perspectiva de las estructuras urbanas ${ }^{51}$, si las ciudades islámicas se caracterizaron por una notable centralización de las distintas funciones en torno a la mezquita aljama, la etapa castellana dio entrada a un policentrismo, en algunos casos, diferencial, en las ciudades más importantes. En estas, a los espacios de centralidad heredados de la etapa andalusí se fueron sumando otros, en parte, consecuencia, de los cambios introducidos en los momentos finales de aquella etapa. En Jaén, Sevilla y, quizá, Jerez de la Frontera, la construcción de nuevas mezquitas aljamas por los almohades, ubicadas en un extremo de las respectivas ciudades, supuso generar nuevos ámbitos de centralidad. Estos se vieron reforzados cuando los castellanos, tras la conquista, transformaron esas mezquitas en catedrales o iglesias colegiales, y en torno a ellas, ubicaron, además, centros administrativos, económicos, culturales, etc. En Córdoba y en Écija, donde la etapa almohades no tuvo la misma significación, se observa igualmente la aparición de nuevas áreas de centralidad.

Consecuencia directa del citado policentrismo fueron los cambios en la estructura del viario, con la puesta en valor de nuevas vías, que comunicaron las puertas de la ciudad con esos centros y las que los pusieron en contacto entre sí. En Córdoba, supuso el desplazamiento del eje norte sur hacia oriente, desde la Puerta Osario a la Puerta del Rincón. En Sevilla permaneció el que unía la Puerta de Carmona con la zona de la primitiva aljama, convertida en centro de abastecimiento de la ciudad, y surgió otro, para unir la Catedral con la Puerta del Arenal, por la que se accedía a la zona portuaria.

Por lo que se refiere a nuevos ejes internos, quizá el ejemplo más llamativo sea la calle de la Feria, de Córdoba, al unir tres centros: el primitivo, en torno a la ahora catedral, la nueva área comercial, centrada en la plaza del Potro, y el administrativo y económico del Salvador-Puerta de Hierro. Por lo que respecta a Sevilla, el Barrio de Francos, que comunicaba los dos centros, el de la Catedral

${ }^{51}$ Lo que sigue se puede encontrar más desarrollado en Collantes de Terán Sánchez, A.: «De la ciudad andalusí a la castellana: el espacio urbano en la Andalucía bajomedieval», en Minervae Baeticae. Boletín de la Real Academia Sevillana de Buenas Letras, 37, 2009, pp. 163-190. 
y el primitivo, en torno a la Colegial del Salvador (antigua mezquita aljama). En Jaén, la nueva calle Maestra.

A diferencia de cómo evolucionaron los mayores centros urbanos, los de rango medio o pequeño tendieron a concentrar las distintas funciones de centralidad en un único espacio. Sería el caso de Baeza, Carmona, Écija, o Úbeda.

Si la consolidación del policentrismo supuso un cambio significativo de la ciudad de la etapa castellana, con relación a la andalusí, no se puede decir lo mismo por lo que respecta a la morfología de esa misma ciudad heredada. Es cierto que desde el primer momento se advierten decisiones, cuya aplicación suponía la transformación del viario estrecho y complicado, que se ha venido considerando como propio del urbanismo andalusí. Cuando la existencia de fuentes escritas lo permiten o, en su caso, la arqueología, se observa la existencia de medidas tendentes a hacer las calles más anchas y rectas, así como a mejorar las condiciones de salubridad de las mismas, mediante la supresión de pisos volados, arquillos, ajimeces, etc. Lo que ocurre es que dichas intervenciones se desarrollaron a una escala microscópica, por lo que solo transcurrido un amplio lapso de tiempo evidenciarían la citada transformación.

Otra manifestación del cambio morfológico fue una significativa desaparición de adarves o calles sin salida, mediante su integración en alguna de las casas colindantes, y consecuentemente, segregándolas del espacio público. Si la función de los adarves había sido permitir el acceso a viviendas situadas en el interior de las manzanas, su desaparición venía a poner de manifiesto una tendencia hacia la concentración de las parcelas, lo que hacía innecesaria su existencia.

Frente a la desaparición del adarve, la apertura de nuevas calles mediante la ruptura de manzanas en el contexto de crecimientos urbanos. Algunas de las citadas operaciones fueron protagonizadas por comunidades religiosas, masculinas y femeninas, que parcelaron huertas de sus conventos. Lo lógico es que en estas operaciones se implantase la parcela denominada gótica, que igualmente se generalizó en las zonas de crecimiento urbano en las periferias de las ciudades consolidadas, intra y extramuros. De ahí, que en estos sectores se generase un urbanismo dominado por calles rectas, que conformaron manzanas rectangulares, como se puede observar en Baeza, Carmona, Córdoba, Écija, Jaén, Sevilla, etc.

Un poderoso instrumento de transformación morfológica fue la proliferación de espacios abiertos en el denso urbanismo andalusí. En los primeros momentos, mediante el derribo de casas para abrir los cementerios parroquiales, como ejemplifica el repartimiento de Jerez de la Frontera ${ }^{52}$. Más adelante, ya

\footnotetext{
52 González Jiménez, M., González Gómez, A. El libro del repartimiento de Jerez de la Frontera,
} estudio y edición, Cádiz, 1980, p. 15, nº 80. 
en el siglo XV la aparición de plazas, promovidas por los concejos o por los particulares, en este caso, como instrumento para realzar las perspectivas de sus casas-palacios. En este mismo orden de cosas, la innovación principal fue la formalización de lo que en Castilla se denominaron plazas mayores, las cuales, en las principales ciudades andaluzas, respondieron a una variada tipología por su ubicación. En Jaén, junto a la catedral; en Jerez de la Frontera, junto a la parroquia de S. Dionisio, centro de la ciudad. En Córdoba, la Corredera, surgió de la urbanización de un sector sin cualificar, pero próximo al nuevo centro urbano del Salvador-Puerta de Hierro. En Sevilla, la plaza de S. Francisco se ubicó en un espacio intermedio entre el antiguo centro del Salvador y el nuevo de la Catedral, y en la confluencia de tres barrios con nombres significativos: los de Francos, de Génova y de la Mar.

En fin, por lo que se refiere a la casa, como acabo de expresar, en toda la zona de expansión y en operaciones dentro de la ciudad consolidada se fue implantando la parcela gótica y con ella el modelo de vivienda occidental, así como de las casas-palacios de la Meseta. Sin embargo, esto, en modo alguno supuso la desaparición de la casa heredada de la etapa andalusí, sino todo lo contrario. Tanto las excavaciones arqueológicas como la documentación escrita reflejan su fuerte implantación a lo largo de toda la Baja Edad Media y su penetración en los siglos de la modernidad. Entendiéndose por continuidad que cuando las casas de origen andalusí se derribaron, sobre ellas se levantaron otras con la misma estructura básica; es decir, organizadas en torno a un patio, dotado, cuando las dimensiones de la parcela lo permitía, de galerías en uno o varios de sus frentes, y con otros espacios abiertos, en la periferia de la parcela, los denominados corrales o trascorrales, jardines o huertas. Casas, además, caracterizadas por el hecho de que no siempre contaron con dos plantas o esta segunda fue solo consecuencia de una fase posterior de crecimiento, por lo que las habitaciones principales se ubicaron en la planta baja, siguiendo ese modelo heredado, cualquiera que fuese la condición social de su inquilino o propietario. Por tanto, poniendo de relieve la existencia de una aceptación consciente del citado modelo, sin lo cual, no hubiera sido posible la mencionada continuidad estructural. 